\title{
Numerical Optimization of the Position in Femoral Head of Proximal Locking Screws of Proximal Femoral Nail System; Biomechanical Study
}

\author{
Mehmet Nuri Konya1, Özgür Verim² \\ ${ }^{1}$ Department of Orthopeadics and Traumatology, Afyon Kocatepe University School of Medicine, Afyon, Turkey \\ ${ }^{2}$ Department of Mechanics, Afyon Kocatepe University School of Engineering, Afyon, Turkey
}

Background: Proximal femoral fracture rates are increasing due to osteoporosis and traffic accidents. Proximal femoral nails are routinely used in the treatment of these fractures in the proximal femur.

Aims: To compare various combinations and to determine the ideal proximal lag screw position in pertrochanteric fractures (Arbeitsgemeinschaft für Osteosynthesefragen classification 31-A1) of the femur by using optimized finite element analysis.

Study Design: Biomechanical study.

Methods: Computed tomography images of patients' right femurs were processed with Mimics. Afterwards a solid femur model was created with SolidWorks 2015 and transferred to ANSYS Workbench 16.0 for response surface optimization analysis which was carried out according to anterior-posterior $\left(-10^{\circ}<\right.$ anteriorposterior $\left.<10^{\circ}\right), \quad$ inferior-superior $\quad\left(-6^{\circ}<\right.$ inferiorsuperior $\left.<7^{\circ}\right)$ and tip-apex distance $(10 \mathrm{~mm}<$ tip-apex distance $<30 \mathrm{~mm}$ ) proximal lag screw positions in the fracture region. The optimum position of the proximal lag screw was determined based on the von Mises stress values occurring on the fracture line. Initial analysis of the system was realized under the surgeon's normal positioning conditions (anterior-posterior, inferiorsuperior $=0^{\circ}$; tip-apex distance $=12 \mathrm{~mm}$ ).
Results: The maximum and minimum (compression) von Mises stresses were found to be $438 \mathrm{MPa}$ and 0.003 $\mathrm{MPa}$, respectively, and risky stresses for the system occurred in the regions where the proximal lag screw passes through the proximal femoral nail hole, the small diameter portion of stem joints with a large diameter and lag screw mounts to the stem. The most suitable position of the proximal lag screw was found at the middle position of the tip-apex distance $(20 \mathrm{~mm})$ and femoral neck (anterior-posterior, inferior-superior $=0^{\circ}$ ), according to von Mises compression stress values occurring on the fracture line.

Conclusion: In our study, we couldn't find any correlation between proximal lag screw movement and tip-apex distance on stresses of the fracture surfaces, but the proximal lag screw position in the inferior (inferiorsuperior $<0$ )-superior (inferior-superior $>0$ ) and posterioranterior directions of the femur neck significantly increased these stresses. The most suitable position of the proximal lag screw was confirmed as the middle of the femoral neck by using optimized finite element analysis.

Keywords: Femoral neck fractures, biomechanics, finite element analysis

Address for Correspondence: Dr. Mehmet Nuri Konya, Department of Orthopeadics and Traumatology, Afyon Kocatepe University School of Medicine, Afyon, Turkey e-mail: nurikonya@hotmail.com

Received:12 May $2016 \quad$ Accepted: 24 March 2017•DOI: 10.4274/balkanmedj.2016.0732

Available at www.balkanmedicaljournal.org

Cite this article as:

Konya MN, Verim Ö. Numerical Optimization of the Position in Femoral Head of Proximal Locking Screws of Proximal Femoral Nail System; Biomechanical Study. Balkan Med J 2017;34:425-31

${ }^{\circ}$ Copyright 2017 by Trakya University Faculty of Medicine / The Balkan Medical Journal published by Galenos Publishing House. 
Incidence of hip fracture is increasing continuously due to increased average age and osteoporosis (1-3). Biomechanical studies have enounced that intramedullary and cephalomedullary devices provide a stable structure for pertrochanteric fractures (4-6). Pertrochanteric fracture [Arbeitsgemeinschaft für Osteosynthesefragen (AO)-OTA 31-A1] lines (7) can start from anywhere on the greater trochanter to above or below the lesser trochanter (Figure 1). These pertrochanteric fractures may be treated with a cephalomedullary nail, sliding hip screw or platescrew fixation (8). The ideal position of the proximal lag screw (PLS) within the femoral head to provide optimal stability to the implant-bone structure has not been studied sufficiently for cephalomedullary nails (9-11). Tip-apex distance (TAD) has been shown to be an important predictor for cut-out of the PLS in cephalomedullary nails (12). Although there is general consensus that the PLS in the middle of femur neck is optimal, there is continuing debate about the ideal position of the PLS (9-13). Our study confirms the importance of the concepts of a suitable TAD, anterior-posterior angle, and inferior-posterior angle as a clinically useful way of describing the suitable position of the PLS. In our study, we aimed to compare various combinations and to determine the ideal position of the PLS in pertrochanteric fractures of the femur by using optimized finite element analysis (FEA).

\section{MATERIALS AND METHODS}

FEA was used to evaluate the importance of adequate positioning of the PLS within the femoral head. Initial analysis of the system was realized under the patients' normal positioning conditions [anterior-posterior (AP), inferior-superior (IS) $=0^{\circ}$; $\mathrm{TAD}=12 \mathrm{~mm}]$.

\section{Reconstruction of three-dimensional models from computed tomography}

This study was approved by the institutional ethics committee (Afyon Kocatepe University Local ethics committee No: 2015/11/300). In our study we used femur computed tomography (CT) images of adult males with no orthopaedic disorders selected from a stored hospital imaging archive with blind selection; for this reason there was no need for patient informed consent forms. Images with 512x512 pixel resolution were obtained using a Sensation 40 CT (Siemens, Erlangen, Germany) and device adjustments were set to $120 \mathrm{kV}$ and $187.5 \mathrm{~m}$. CT images were processed with Mimics software

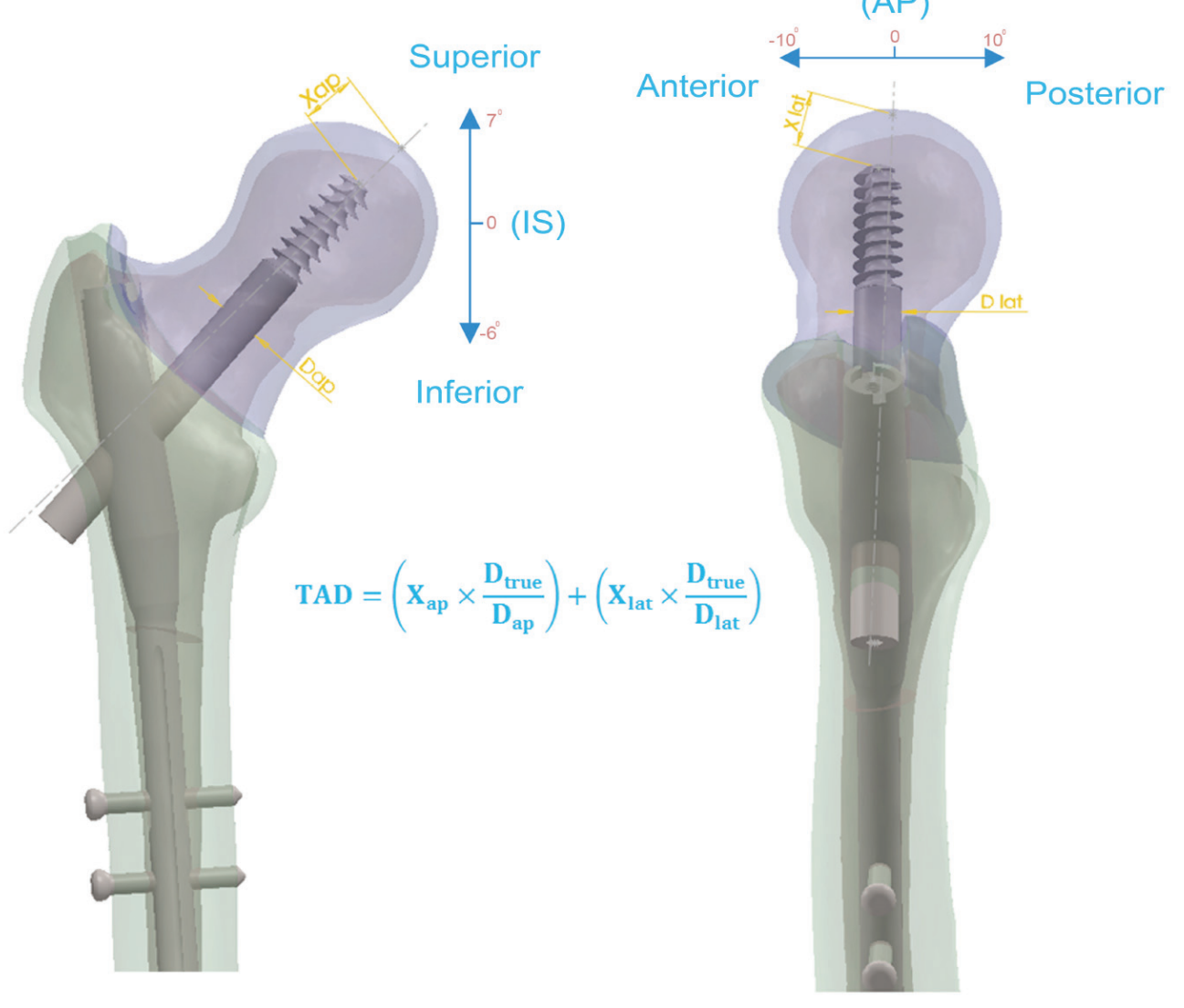

FIG. 1. Simulation of AO 31-A1 fracture and description of tip-apex distance. 
(Materialise, Leuven, Belgium). A total of 665 DICOM (Digital Imaging and Communications in Medicine) images of human femurs with $1 \mathrm{~mm}$ slice thickness and $0.6 \mathrm{~mm}$ pixel size were analysed. Models were transformed into non-uniform rational basis spline surface format with SolidWorks 2015 software using point cloud methods.

Intertrochanteric femur fracture was simulated according to AO classification 31-A1 in three-dimensional (3D) modelling software (SolidWorks).

\section{Fea of the cephalomedullary nail}

The cephalomedullary nail on the human femur head was analysed with FEA determined under loading conditions $(7,14)$. Material properties of all components were assigned as linear elastic isotropic. All materials of the cephalomedullary nail were made of Ti6Al4V (titanium 6, aluminium 4, vanadium alloy) with a modulus of elasticity value of $114 \mathrm{GPa}$. A value of 0.3 was assigned to all the material Poisson ratios. The modulus of elasticity of the trabecular and cortical components of the femur was taken as $0.86 \mathrm{GPa}$ and $16.8 \mathrm{GPa}$, respectively (15). Our study simulated the stance phase of walking which is the most commonly used position in virtual environment studies (Figure 2). Finite element models of the proximal femoral

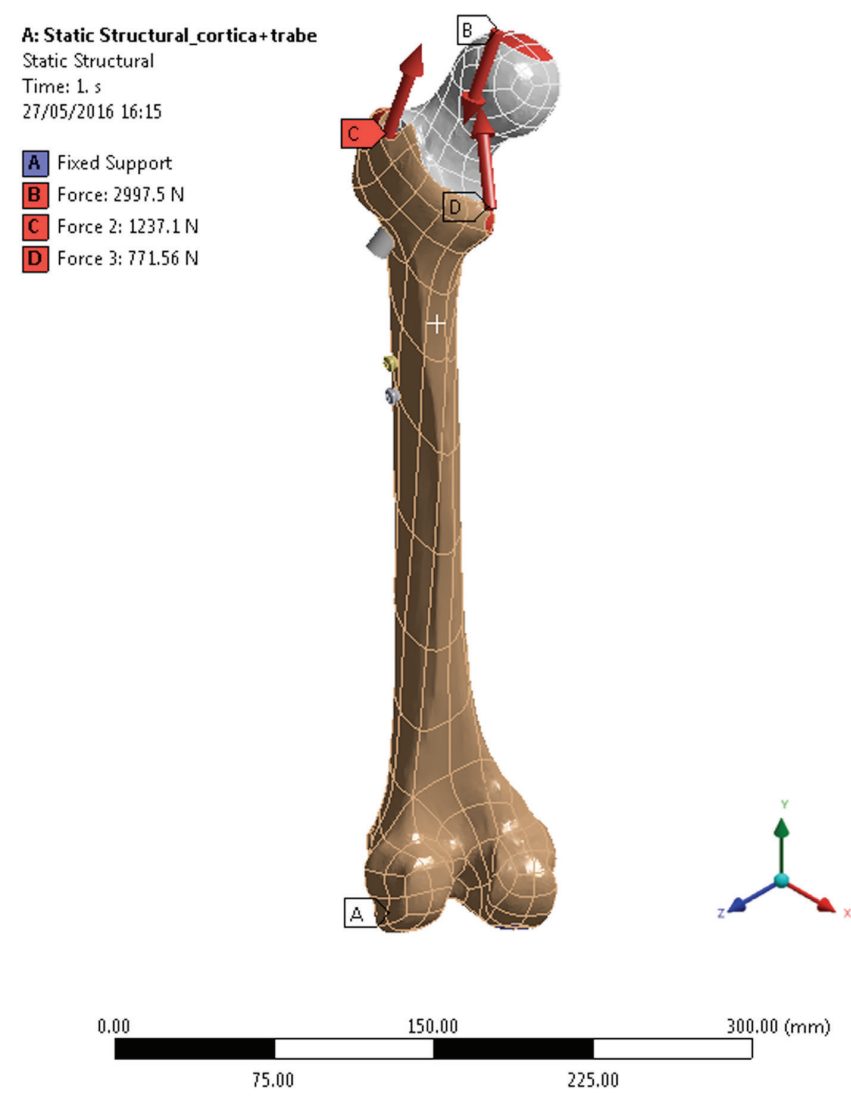

FIG. 2. Loading condition of the femoral head. nail (PFN) and bone system were composed of approximately 1526424 elements and 2224310 nodes. 3D 10-node tetrahedral structural solid elements were used to model the whole system. The element size was $3 \mathrm{~mm}$ for the cortical bone, and the contact size between the PFN and the trabecular bone was 1 $\mathrm{mm}$. In this study, the main force (applied to the femoral head at $23^{\circ}$ on the frontal and $6^{\circ}$ on the sagittal planes) was taken to be 2460 N. Forces of the abductor and the iliopsoas muscles were taken as $1700 \mathrm{~N}\left(24^{\circ}\right.$ on the frontal and $15^{\circ}$ on the sagittal planes) and $771 \mathrm{~N}\left(41^{\circ}\right.$ on the frontal and $26^{\circ}$ on the sagittal planes), respectively $(7,14)$.

\section{Implant design}

We used an uncemented 3D model of modular nail prosthesis combination [modular prosthesis nail combination $\left(\mathrm{MNP}^{\circledR}\right)$; Neologic Sağlık Hizmetleri, İzmir, Turkey] in this study. MNP is a newly designed modular hip system which combines a PFN and hip prosthesis. The femoral stem of this implant can be used as either a PFN or hip arthroplasty stem and also the can easily convert to a hip prosthesis by changing one part (Figure 3a, 3b).

\section{Optimization of the lag screw position}

The response surface optimization method is a combination of mathematical expressions and statistical techniques used to analyse a response that is affected by several variables and to optimize the response. For many response surface methods, there is a need to estimate the mathematical forms of the

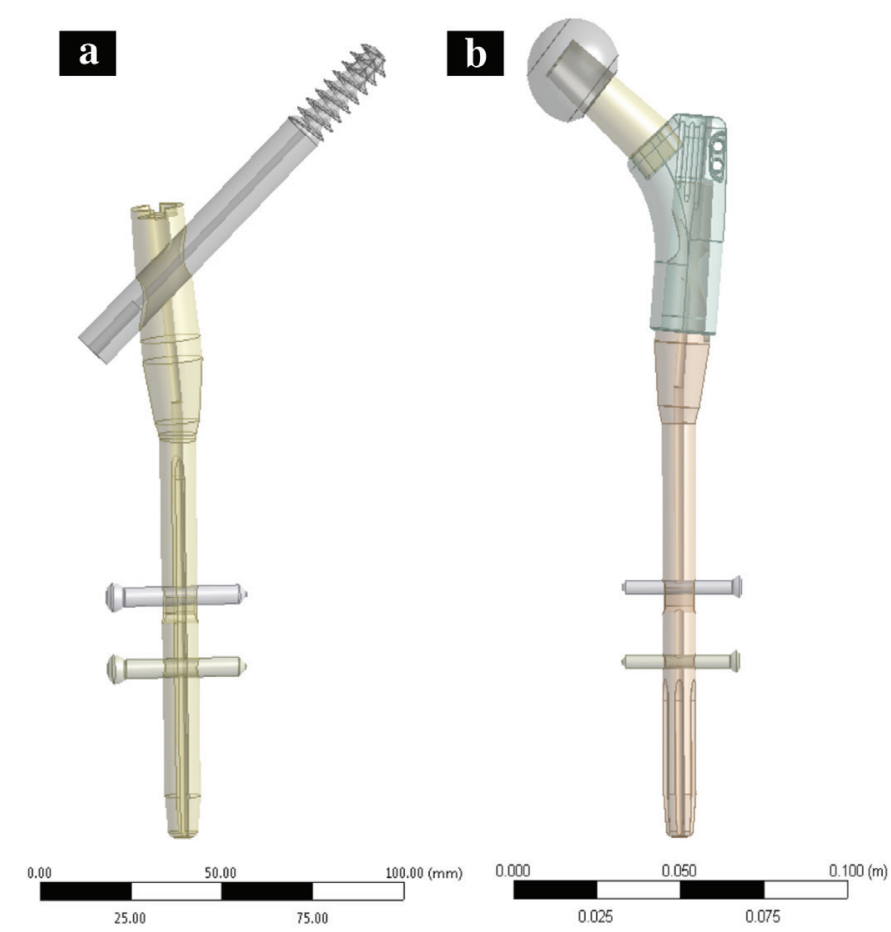

FIG. 3. Modular nail prosthesis: (a) PFN, (b) hip prosthesis. 
functions between the response and the independent variables in the problems (16). If there is a curvature in the response surface of the system, a second order equation is needed, as follows:

$$
y=\beta_{0}+\sum_{j=1}^{k} \beta_{j} x_{j}+\sum_{j=1}^{k} \beta_{j j} x_{j}^{2}+\sum_{i}^{k j 1} \sum_{j}^{k} \beta_{i j} x_{i} x_{j}+j
$$

A linear relationship of parameters was developed using the product moment correlation coefficient of Spearman and Pearson. A correlation-sensitivity matrix was generated to show the correlation between input and output parameters and the sensitivity of output parameters according to input parameters. The lower, initial and upper values for the input parameters used in the DOE (design of experiment) workspace are given in Table 1.

TABLE 1. Input parameters of the proximal locking screw position

\begin{tabular}{lccc}
\hline & $\begin{array}{c}\text { Lower value } \\
(\mathrm{mm})\end{array}$ & $\begin{array}{c}\text { Initial value } \\
(\mathrm{mm})\end{array}$ & $\begin{array}{c}\text { Upper value } \\
(\mathrm{mm})\end{array}$ \\
\hline $\mathrm{AP}\left(^{\circ}\right)$ & -10 & 0 & 10 \\
$\mathrm{IS}\left(^{\circ}\right)$ & -6 & 0 & 7 \\
$\mathrm{TAD}(\mathrm{mm})$ & 10 & 12 & 30 \\
\hline AP: anterior-posterior; IS: inferior-superior; TAD: tip-apex distance; mm: millimetre
\end{tabular}

\section{RESULTS}

In this study, the most suitable position of the lag screw and FEA of the cephalomedullary nail implanted on the human femur were examined. According to the results of the analysis of the current system, the maximum and minimum (compression) von Mises stresses were found to be $438 \mathrm{MPa}$ and $0.003 \mathrm{MPa}$, respectively, and risky stresses for the system occurred in the regions where the PLS passes through the PFN hole, the small diameter portion of stem joints with a large diameter and lag screw mounts to the stem (Figure $3 \mathrm{a}, \mathrm{b}$ ).

The maximum stresses on the cephalomedullary nail occurred at the start of the stem slope (Figure 4) and stress on the cephalomedullary nail was obtained as $438 \mathrm{MPa}$. The maximum stress on the PLS was 100.4 MPa in the region where the PLS passes through the PFN hole (Figure 4), but none of the stresses occurring on the components exceeded the yield strength of the materials (Figure 4c-4e). When the stresses on the fracture line were taken into consideration according to the results of the optimization, 3D diagrams of the response surface of the parameters were reported (Figure 5).

The most suitable position of the lag screw was found at the middle position of the TAD $(20 \mathrm{~mm})$ and femoral neck (AP,
IS $=0^{\circ}$ ), according to von Mises compression stress values occurring on the fracture line. In our study, we couldn't find any correlation with PLS movement and TAD on fracture line stress distribution, but PLS positions in the inferior (IS $<0$ )-superior $(\mathrm{IS}>0)$ and anterior $(\mathrm{AP}<0)$-posterior $(\mathrm{AP}>0)$ regions of the femur neck significantly increased these stresses. The most suitable position of the PLS, confirmed by clinical experience in the literature, is in the middle of the femoral neck and TAD (9-11). The worst position of the PLS is in the anterior, posterior, superior region of the femoral neck. But in this context, the risk of damage of the components was not observed.

We also determined screw displacement in every direction. According to these results screw displacement in the AP direction was $-15.32 \mathrm{~mm}$, mediolateral direction $0.3 \mathrm{~mm}$, and SI direction $0.2 \mathrm{~mm}$ (Figure 4b).

\section{DISCUSSION}

Proximal femur fractures are generally treated with internal fixation or arthroplasty (3). Both treatment regimes have advantages and disadvantages. Internal fixation consists of intramedullary techniques such as PFN and extramedullary techniques such as dynamic hip screw or plate and screw fixation techniques. In either intramedullary or extramedullary techniques, the femoral head must be stabilized with screws. The proximal femoral screw position in both techniques is important for fracture healing. In our literature review for the best screw position, some previous studies were found. Some authors reported suitable screw positions correlated with clinical experience and reported the failure rate as 6-16\% (17). Screw positioning and lag screw cut-out reasons are discussed in many studies. Most of these studies are based on clinical experience and studies done retrospectively. In this study, our FEA was totally blinded and aimed to determine different location combinations such as AP, medial-lateral, and inferiorposterior positions of the lag screw.

Kane et al. (18) discussed the importance of TAD in a cadaveric study and found that the most suitable position and found no significant differences between low-centre and centre-centre screw position treatment groups but they didn't evaluate various screw configurations in the coronal and sagittal planes and their correlation. We evaluated nearly every point of the femoral head in different directions and load bearing either of lag screw or fracture lines.

Goffin et al. (10) tried to find the most suitable PLS position in a finite element study by using nine different positions manually. Screw positions were evaluated with the lag screw and proximal bone fragment (head and neck) and the safest seemed to be inferior middle and inferior posterior positions. A navigation system improved the lag screw position according to Regling 


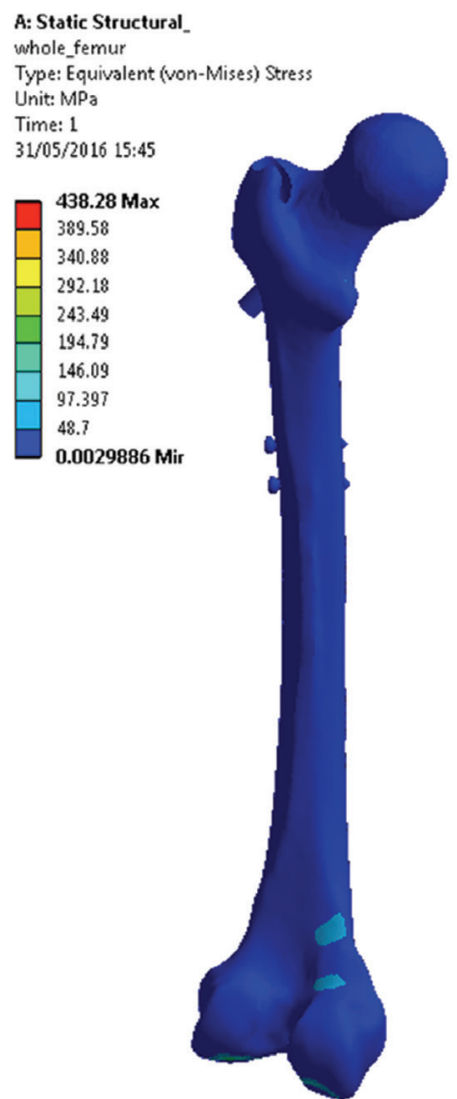

(a)

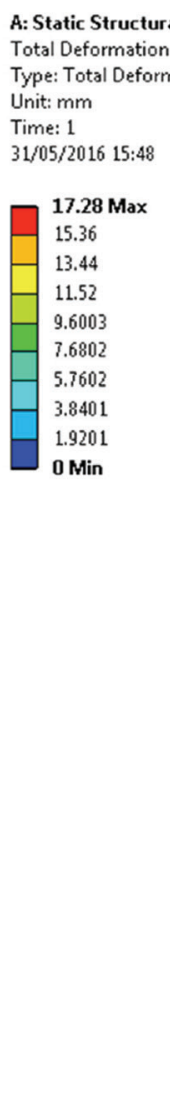

Total Deformation

Type: Total Deformation

Time: 1

$31 / 05 / 2016 \quad 15: 48$

\begin{tabular}{|l}
$\mathbf{1 7 . 2 8}$ Max \\
15.36 \\
13.44 \\
11.52 \\
9.6003 \\
7.6802 \\
5.7602 \\
3.8401 \\
1.9201 \\
0 Min
\end{tabular}

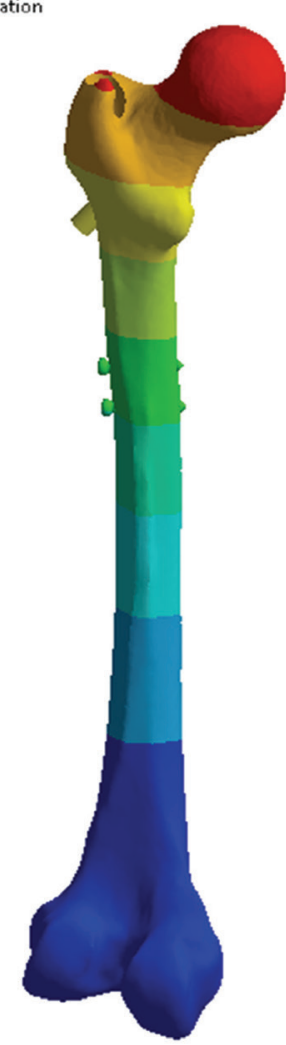

(b)
A: Static Structural.

Stem_Equivalent_Stress

Type: Equivalent (von-Mises) Stross

Unit: $\mathrm{MPa}$

Time: 1

$31 / 05 / 201615: 50$

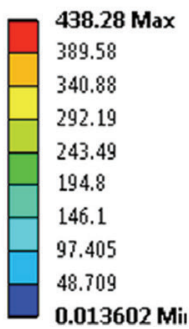

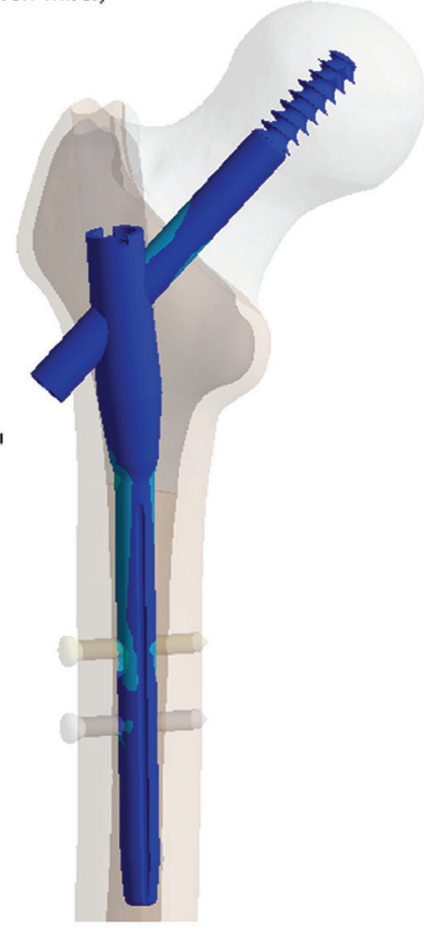

(c)

A: Static Structural_cortica+trabecular

Screw_Equivalent_Stress

Type: Equivalent (von-Mises) Stress

Unit: $\mathrm{MPa}$

Time: 1

$31 / 05 / 201615: 53$

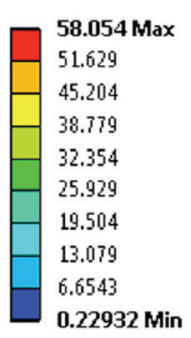

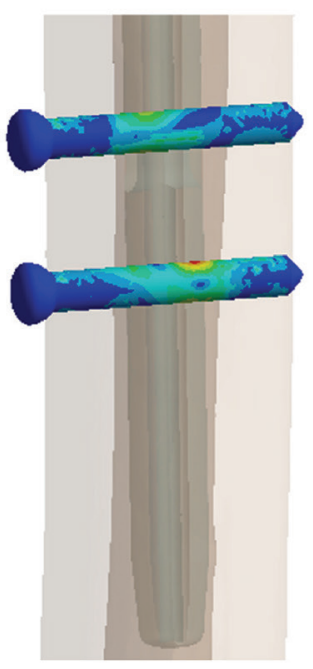

(d)

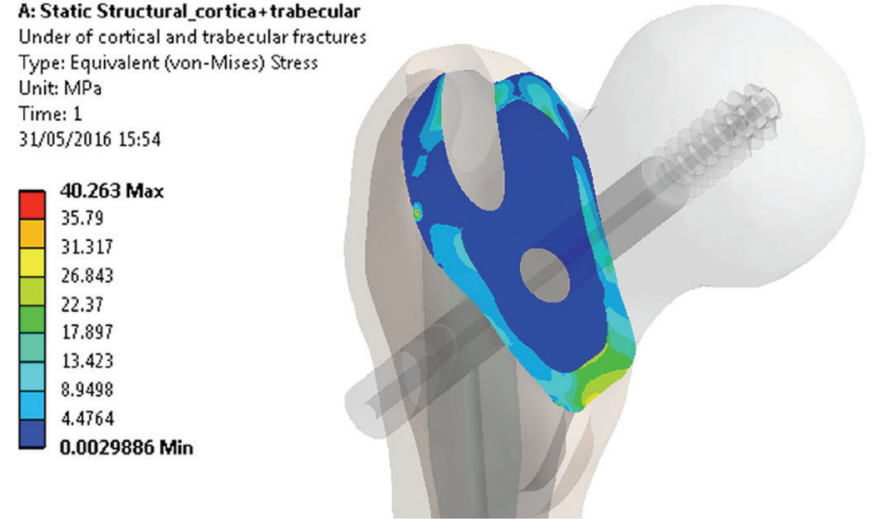

(e)

FIG. 4. (a, b) Equivalent von Mises stress and total deformation of the cephalomedullary nail and femur, (c) stresses on the cephalomedullary nail, (d) stresses on the locking screw, (e) stresses on the fracture line of the pertrochanteric fracture. 


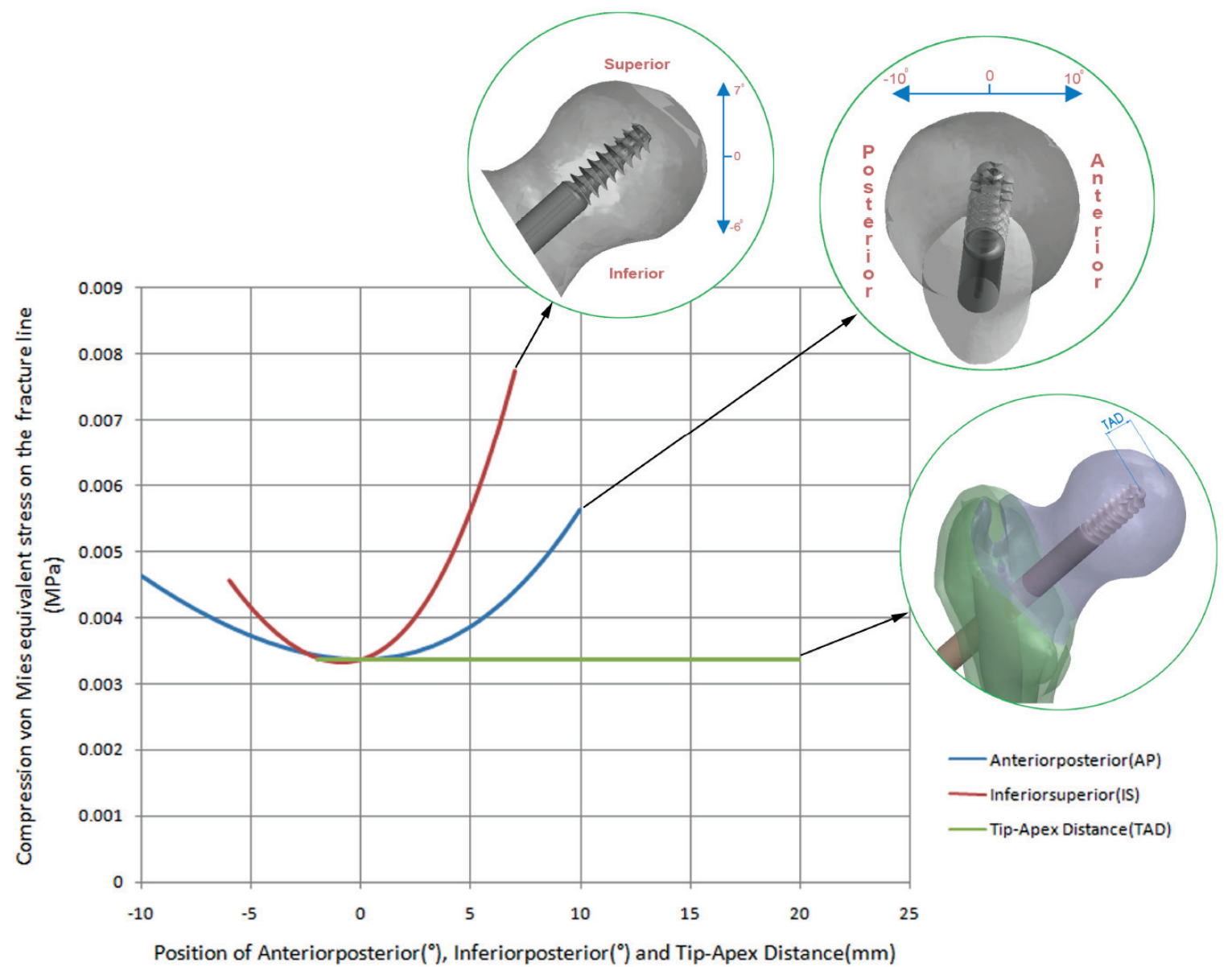

FIG. 5. Von Mises stress distribution on the fracture line according to screw position in three planes, tip-apex distance (mm), AP $\left({ }^{\circ}\right)$ and IS $\left({ }^{\circ}\right)$.

et al. (19) cadaveric study in operations carried out by less experienced and experienced surgeons and the median TAD was $12 \mathrm{~mm}$ and $13 \mathrm{~mm}$, respectively. In another study, Hrubina et al. (9) reported 297 patients with 308 hips treated with a dynamic hip screw; the complication rate was reported as $10 \%$ and the re-operation rate as $3.9 \%$. In our clinical experience, there are two malpositions of the PFN which can cause pull-out of the nail but no delay or non-union in the fracture line. Munemoto et al. (20) reported hip multidetector row CT in 10 elderly patients and found the highest bone microstructure quality, in the weight-bearing part, in the superior site of the femoral head. In the femoral neck the greatest bone quality was found in the inferior region. But this study was conducted on elderly patients only and didn't evaluate healthy people, which was reported as a limitation. As reported above, bone imaging of elderly people was used in our study; we evaluated CT images from healthy persons and the position of the proximal femoral screw was determined automatically from the program. AP, IS, and TAD measurements were evaluated. In our study the safest position is at the middle position of the TAD $(20 \mathrm{~mm})$ and femoral neck
(AP, IS $=0^{\circ}$ ), according to von Mises compression stress values occurring on the fracture line.

If the lag screw is not in an adequate position, the load can cause excess stress and this can lead to the failure of components. But, according to results of our study, the stresses on all components did not exceed the yield stress. Our study cannot perform prospectively any exact prediction of complications. In our study, according to optimized FEA, the most suitable position was found to be the middle position of the TAD $(20 \mathrm{~mm})$ and femoral neck ( $\mathrm{AP}, \mathrm{IS}=0^{\circ}$ ), according to von Mises compression stress values occurring on the fracture line. When mechanical properties of the bone and implant of each patient are entered into the FEA, the position of the lag screw can be estimated. Future studies should consider the results of the developed FEA compared to in vivo and mechanical tests with different kinds of implant and, as a clinical study, the impact of the screw position on fracture healing.

There are several limitations to note in this study. This research was a biomechanical study so we couldn't simulate the fracture 
healing stages. In internal fixation devices for intertrochanteric fracture, whichever is used, lag screws pull the head to the shaft of the femur for compression which can cause femoral neck shortening and lag screws slides laterally (21). Another limitation is that we couldn't compare the results for the femurs of patients of different gender. Strengths of this study are comparing multiple screw positions in different directions in the femoral head with optimized FEA of a newly developed PFN. In our study, we couldn't find any correlation between PLS movement and TAD on stresses of the fracture surfaces, but the PLS position in the inferior (IS $<0$ )-superior (IS $>0$ ) and posterior-anterior directions of the femur neck significantly increased these stresses. The most suitable position of the PLS was confirmed as the middle of the femoral neck and TAD by using optimized FEA.

Financial Disclosure: This study was supported by Afyon Kocatepe University Scientific Research Project Coordination Unit 16 KARIYER 40 Project number date 11.05.2016. This study supported by Turkish Society of Orthopeadics and Traumatology Research Councile Project number 23/date 06.02.2014.

Conflict of Interest: No conflict of interest was declared by the authors.

\section{REFERENCES}

1. Mereddy P, Kamath S, Ramakrishnan M, Malik H, Donnachie N. The AO/ ASIF proximal femoral nail antirotation (PFNA): a new design for the treatment of unstable proximal femoral fractures. Injury 2009;40:428-32.

2. Verheyden AP, Josten C. Intramedullary Fixation of Intertrochanteric Fractures with the Proximal Femoral Nail (PFN). Operat Orthop Traumatol 2003;15:20-37.

3. Sener M, Onar V, Kazlmoğlu C, Yağdi S. [Mortality and morbidity in elderly patients who underwent partial prosthesis replacement for proximal femoral fractures]. Eklem Hastalik Cerrahisi 2009;20:11-7.

4. Curtis MJ, Jinnah RH, Wilson V, Cunningham BW. Proximal femoral fractures: a biomechanical study to compare intramedullary and extramedullary fixation. Injury 1994;25:99-104.

5. Kuzyk PR, Zdero R, Shah S, Olsen M, Waddell JP, Schemitsch EH. Femoral head lag screw position for cephalomedullary nails: a biomechanical analysis. J Orthop Trauma 2012;26:41-21.
6. Wu X, Yang M, Wu L, Niu W. A Biomechanical Comparison of Two Intramedullary Implants for Subtrochanteric Fracture in Two Healing Stages: A Finite Element Analysis. Appl Bionics Biomech 2015:1-7.

7. Oken OF, Soydan Z, Yildirim AO, Gulcek M, Ozlu K, Ucaner A. Performance of modified anatomic plates is comparable to proximal femoral nail, dynamic hip screw and anatomic plates: finite element and biomechanical testing. Injury 2011;42:1077-83.

8. Azboy I, Demirtaş A, Gem M, Cakır IA, Tutak Y. A comparison of proximal femoral locking plate versus 95-degree angled blade plate in the treatment of reverse intertrochanteric fractures. Eklem Hastalik Cerrahisi 2014;25:15-20.

9. Hrubina M, Horák Z, Bartoška R, Navrátil L, Rosina J. Computational modeling in the prediction of Dynamic Hip Screw failure in proximal femoral fractures. J Appl Biomed 2013;11:143-51.

10. Goffin JM, Pankaj P, Simpson AH. The importance of lag screw position for the stabilization of trochanteric fractures with a sliding hip screw: a subject-specific finite element study. J Orthop Res 2013;31:596-600.

11. Kuzyk P, Higgins G, Zedero R, Shah S, Olsen M, Wadell J, et al. Femoral head lag screw position for cephalomedullary nails: a biomechanical analysis. J Orthop Trauma 2012;26:414-21.

12. Kashigar A, Vincent A, Gunton MJ, Backstein D, Safir O, Kuzyk PR. Predictors of failure for cephalomedullary nailing of proximal femoral fractures. Bone Joint J 2014;96:1029-34.

13. Baumgaertner MR, Solberg BD. Awareness of tip-apex distance reduces failure of fixation of trochanteric fractures of the hip. J Bone Joint Surg Br 1997;79:969-71.

14. Seral B, García JM, Cegoñino J, Doblaré M, Seral F. Finite element study of intramedullary osteosynthesis in the treatment of trochanteric fractures of the hip: Gamma and PFN. Injury 2004;35:130-5.

15. Mei J, Liu S, Jia G, Cui X, Jiang C, Ou Y. Finite element analysis of the effect of cannulated screw placement and drilling frequency on femoral neck fracture fixation. Injury 2014;45:2045-50.

16. Kilickap, E. and Huseyinoglu M. Optimization and modelling of burrheight by using response surface methodology and genetic algorithm in drilling AISI 316. J Eng Fac Eng Dicle Univ 2010;1:71-80.

17. Gundle R, Gargan MF, Simpson AH. How to minimize failures of fixation of unstable intertrochanteric fractures. Injury 1995;26:611-4.

18. Kane P, Vopat B, Heard W, Thakur N, Paller D, Koruprolu S, et al. Is tip apex distance as important as we think? A biomechanical study examining optimal lag screw placement. Clin Orthop Relat Res 2014;472:2492-8.

19. Regling M, Blau A, Probe RA, Maxey JW, Solberg BD. Improved lag screw positioning in the treatment of proximal femur fractures using a novel computer assisted surgery method: a cadaveric study. BMC Musculoskelet Disord 2014;15:189.

20. Munemoto M, Kido A, Sakamoto Y, Inoue K, Yokoi K, Shinohara Y, et al. Analysis of trabecular bone microstructure in osteoporotic femoral heads in human patients: in vivo study using multidetector row computed tomography. BMC Musculoskelet Disord 2016;17:13.

21. Min BW, Lee KJ, Bae KC, Lee SW, Lee SJ, Choi JH. Result of Internal Fixation for Stable Femoral Neck Fractures in Elderly Patients. Hip Pelvis 2016;28:43-8. 